\title{
The New Future Pharmacology Journal: A Cutting-Edge Opportunity for Rapidly Sharing and Widely Disseminating the Most Advanced Research Ideas and Findings
}

\author{
Fabrizio Schifano $(\mathbb{D}$
}

check for updates

Citation: Schifano, F. The New Future Pharmacology Journal: A Cutting-Edge Opportunity for Rapidly Sharing and Widely Disseminating the Most Advanced Research Ideas and Findings. Future Pharmacol. 2021, 1, 1-2. https:// doi.org/10.3390/futurepharmacol 1010001

Received: 10 June 2021

Accepted: 10 June 2021

Published: 18 June 2021

Publisher's Note: MDPI stays neutral with regard to jurisdictional claims in published maps and institutional affiliations.

Copyright: (c) 2021 by the author Licensee MDPI, Basel, Switzerland. This article is an open access article distributed under the terms and conditions of the Creative Commons Attribution (CC BY) license (https:// creativecommons.org/licenses/by/ $4.0 /$ )
Psychopharmacology, Drug Misuse and Novel Psychoactive Substances Research Unit, School of Life and Medical Sciences, University of Hertfordshire, Hertfordshire AL10 9EU, UK; F.Schifano@herts.ac.uk

The journal Future Pharmacology (ISSN 2673-9879) [1] is a new open-access journal published quarterly online by MDPI which has attracted an excellent, truly worldwide, editorial team made up by members who are active in the very different and exciting areas of pharmacology research.

The journal publishes full research papers, reviews, and communications. Its mission is to publish cutting-edge articles, conference proceedings, and Special Issues in order to highlight outstanding research. All manuscripts will be thoroughly peer-reviewed in a timely fashion, with a first decision in 15 days and acceptance to publication in 3 days, which is being estimated by the median values for MDPI journals in the first half of 2020.

Indeed, the current Covid-19 pandemic scenario has emphasized not only that science is relevant for the well-being of the individuals but also that the medical-, including the pharmacology-, related research findings will need to be disseminated to the community very rapidly, much faster than what was happening up to only a couple of years ago. As the founding Editor-in-Chief, it is my wish that Future Pharmacology will play an important role in this rapid research dissemination activities.

Future Pharmacology aims to achieve a better understanding and dissemination of pharmacological sciences, with the journal's focus on basic/pre-clinical/clinical pharmacology; drug discovery; and therapeutics.

We will be happy to accept the latest results on a range of issues including, but not limited to: drug design and discovery; drug metabolism; molecular/biochemical/cellular pharmacology; clinical pharmacology (with a special focus on: drug-drug interactions; neuropsychopharmacology; misuse/abuse/dependence on prescribing/over-the-counter/ recreational and new psychoactive substances); behavioral pharmacology; toxicology; pharmacogenetics/pharmacogenomics; and finally biopharmaceuticals.

All articles published in Future Pharmacology will immediately be made available worldwide under an open-access license. This means that everyone, including interested scientists and the general public, will have free and unlimited access to the full text of all articles published in the journal and everyone will be free to reuse the published material given proper accreditation/citation.

To attract high-quality research articles, Future Pharmacology will not charge any publishing fees for manuscripts submitted during 2021.

I believe that this journal will become a leading forum for studies related to basic, preclinical, and clinical pharmacology. I look forward to collaborating with our contributors and readers to make Future Pharmacology a reference for the field.

Conflicts of Interest: The author declares no conflict of interest. 


\section{Reference}

1. Future Pharmacology Home Page. Available online: https://www.mdpi.com/journal/futurepharmacol (accessed on 15 June 2021).

\section{Short Biography of Author}

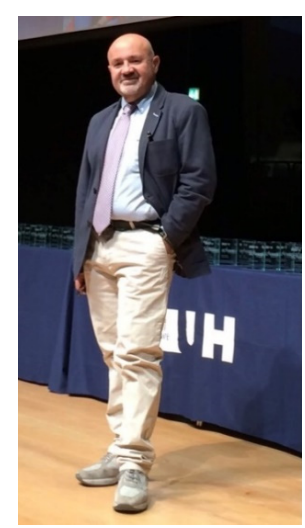

Fabrizio Schifano is a Professor of Clinical Pharmacology and Therapeutics; Head of the 'Psychopharmacology, Drugs of Misuse and Novel Psychoactive Substances' Research Unit, Department of Clinical and Pharmaceutical Sciences, University of Hertfordshire (UK); and Consultant Psychiatrist, Addictions (Drug and Alcohol Hertfordshire Recovery Services, UK). He is one of the very few physicians in Europe with training and specialist qualifications in both (clinical) pharmacology and psychiatry. Over the years, he has been the Principal Investigator of a number of consecutive EU Commission-funded, multi-center (i.e., up to $12 \mathrm{EU}$ countries involved) research programs. 